\title{
One-step endoscopic ultrasound-directed gastro-gastrostomy ERCP for treatment of bile leak
}

A 32-year-old woman with a history of obesity who underwent Roux-en-Y gastric bypass in 2005 presented with acute cholecystitis. She underwent laparoscopic cholecystectomy, which was converted to open cholecystectomy owing to significant inflammation and adhesions. On postoperative Day 2, $300 \mathrm{~mL}$ of bilious output was noted in the JacksonPratt drain, which raised concerns about a bile leak. The gastrointestinal department was consulted for endoscopic retrograde cholangiopancreatography (ERCP) and management of bile leak.

Laparoscopy-assisted ERCP was felt to be high risk and difficult because of the patient's recent open cholecystectomy with significant adhesions and inflammation. Enteroscopy-assisted ERCP was felt to have a low likelihood of success owing to a Roux limb length of $>150 \mathrm{~cm}$. A decision was made to pursue endoscopic ultrasound (EUS)-directed gastro-gastrostomy ERCP in one step (EDGE).

EDGE involves the creation of a gastrogastrostomy fistula to gain access into the bypassed stomach. Conventional ERCP is then performed through the gastro-gastrostomy fistula after fistula maturation, which usually takes 4- 6 weeks. Given the acute bile leak, EDGE was performed in one session with creation of the gastro-gastrostomy fistula tract under EUS guidance using a $15 \mathrm{~mm}$ lumenapposing metal stent ( $>$ Fig. 1 ), followed by conventional ERCP during the same session ( Video 1 ). ERCP showed an active bile leak ( $\mathbf{F i g . 2}$ ), and a fully covered metal stent was placed for biliary drainage.

On postprocedure Day 1, the JacksonPratt drain output was no longer bilious and had decreased in volume. On postprocedure Day 2 the patient was discharged home. The patient returned for outpatient ERCP with stent removal 8 weeks later, and resolution of the bile leak was seen on the cholangiogram. After stent removal, the gastro-gastric

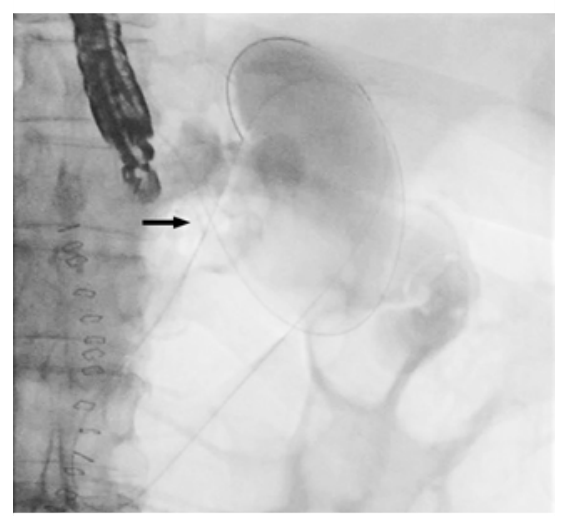

- Fig. 1 Fluoroscopy confirmed placement of the lumen-apposing metal stent (arrow) across the bypassed stomach, creating a gastro-gastrostomy fistula.

fistula tract was closed with endoscopic suturing.

EUS-guided gastro-gastrostomy ERCP has previously been described in a case series as a feasible multi-step alternative approach to balloon-assisted or laparoscopy-assisted ERCP in patients with altered anatomy from gastric bypass [1]. The technical success rate in creation of the gastro-gastrostomy fis-

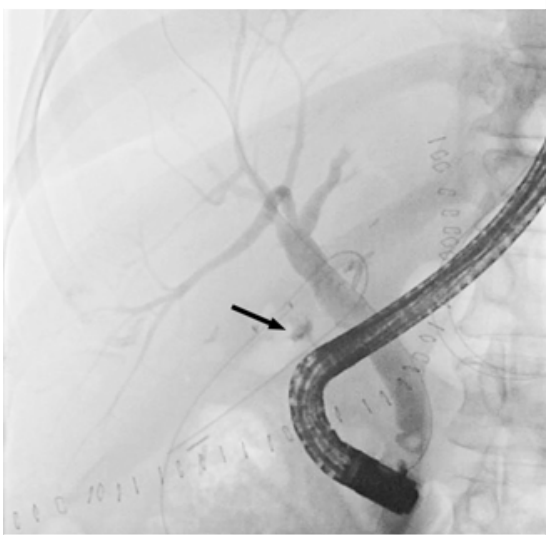

- Fig. 2 Cholangiogram showed a bile leak (arrow) near the cystic duct remnant.

tula was $100 \%$, and successful ERCP via the fistula tract was performed in $60 \%$ of cases. A mid-term follow-up study involving 16 patients showed improved clinical success approaching $90 \%$ [2]. The procedure was typically performed in multiple steps to allow for full maturation of the fistula. We describe here a case of the successful management of bile leak via the EDGE proce-

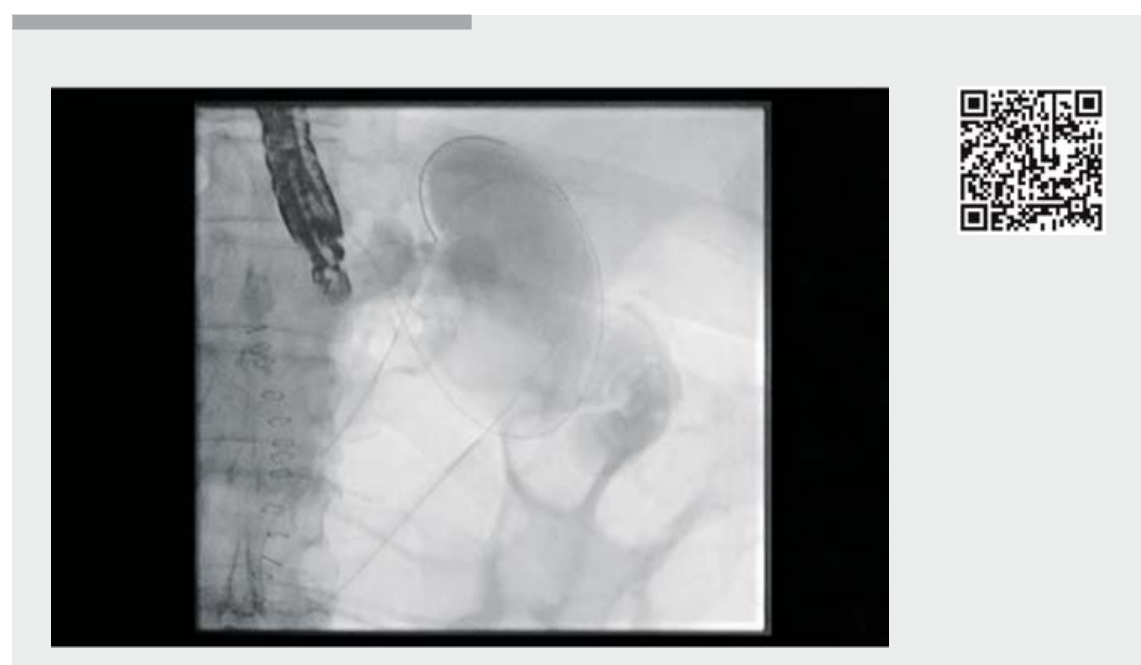

$\checkmark$ Video 1 Endoscopic ultrasound-directed gastro-gastrostomy endoscopic retrograde cholangiopancreatography for the treatment of postoperative bile leak. 
dure in one step, and demonstrate that this is a feasible solution in patients with difficult gastric bypass anatomy who require ERCP.

Endoscopy_UCTN_Code_TTT_1AR_2A

\section{Competing interests}

None

The Authors

Ming-ming Xu ${ }^{1}$, Carlos Carames ${ }^{1}$, Aleksey Novikov ${ }^{1}$, Monica Saumoy ${ }^{1}$, Che Afaneh ${ }^{2}$, Michel Kahaleh ${ }^{1}$, Reem Z. Sharaiha ${ }^{1}$

1 Division of Gastroenterology and Hepatology, New York Presbyterian Hospital Weill Cornell Medical Center, New York, New York, United States

2 Department of Surgery, New York Presbyterian Hospital Weill Cornell Medical Center, New York, New York, United States

\section{Corresponding author}

\section{Reem Z. Sharaiha, MD}

Gastroenterology and Hepatology, Joan and Sanford I Weill Medical College of Cornell University, 1305 York Avenue 4th Floor, New York NY 10021, United States

Fax: +1-646-9620110

rzs9001@med.cornell.edu

\section{References}

[1] Kedia P, Tyberg A, Kumta NA et al. EUS directed transgastric ERCP for roux-en-y gastric bypass anatomy: a minimally invasive approach. Gastrointest Endosc 2015; 82: $560-565$

[2] Tyberg A, Nieto J, Salgao S et al. Endoscopic ultrasound (EUS)-directed transgastric endoscopic retrograde cholangiopancreatography or EUS: mid-term analysis of an emerging procedure. Clin Endosc 2016. DOI: $10.5946 /$ ce. 2016.030

\section{Bibliography}

DOI https://doi.org/10.1055/s-0043-104524

Endoscopy 2017; 49: 715-716

(C) Georg Thieme Verlag KG

Stuttgart · New York

ISSN 0013-726X

\section{ENDOSCOPY E-VIDEOS}

https://eref.thieme.de/e-videos

口76: Endoscopy E-Videos is a free access online section, reporting 口. on interesting cases and new techniques in gastroenterological endoscopy. All papers include a high quality video and all contributions are freely accessible online.

This section has its own submission website at https://mc.manuscriptcentral.com/e-videos 